\title{
Hepatitis C Virus and Alcohol
}

\author{
Larry Siu, M.D. ${ }^{1}$, Julie Foont, M.D. ${ }^{1}$, and Jack R. Wands, M.D. ${ }^{1}$ \\ ${ }^{1}$ Warren Alpert Medical School of Brown University, Providence, Rhode Island
}

\begin{abstract}
This review will focus on the prevalence of hepatitis c virus (HCV) infection in alcoholics with and without liver disease. Evidence will be presented to demonstrate that ethanol and chronic HCV infection synergistically accelerate liver injury. Some of the major postulated mechanisms responsible for disease progression include high rates of apoptosis, lipid peroxidation, and generation of free radicals and reactive oxygen species with reduced antioxidant capacity of the liver.

Acquisition and persistence of $\mathrm{HCV}$ infection may be due to the adverse effects of ethanol on humoral and cellular immune responses to HCV. Dendritic cells (DC) appear to be one of the major targets for ethanol's action and DC dysfunction impairs the ability of the host to generate viral specific cluster of differentiation 4 (CD4+) and cluster of differentiation 8 (CD8+) immune responses. There is a relationship between increased alcohol intake and decreased response to interferon (IFN) therapy, which may be reversed by abstinence. Clinical studies are needed to optimize treatment responses in alcoholic patients with chronic HCV infection.
\end{abstract}

\section{Keywords}

Hepatic C virus; cellular immune response; liver disease

Chronic hepatitis $\mathrm{C}$ virus (HCV) infection is a major cause of liver disease, cirrhosis, and hepatocellular carcinoma (HCC) in alcoholics. ${ }^{1}$ Since chronic ethanol abuse in the setting of persistent $\mathrm{HCV}$ infection accelerates the progression of liver disease, we will focus on several pathogenic mechanisms of how acute and chronic liver injury is produced by both alcohol and $\mathrm{HCV}$ infection. The critical role of the host cellular immune response will be addressed including clinical and pre-clinical studies that document alcohol suppressive effects on generation of viral specific cluster of differentiation $4(\mathrm{CD} 4+)$ and cluster of differentiation 8 (CD8+) immune responses required for HCV elimination from the liver. It appears that dendritic cells (DCs) are a critical cellular target of alcohol, and acute and chronic exposure substantially inhibits the ability of these cells to function as antigen-presenting cells. Because alcohol has effects on interferon- (IFN-) generated signal transduction pathways that modulate immune responses, patients suffering from alcoholism may have suboptimal therapeutic responses to antiviral agents. Reduced efficacy of treatment may also be related to HCV RNA titers, extent of liver fibrosis, increased hepatic fat deposition, and decreased cellular immunity.

\section{EPIDEMIOLOGY}

Studies on the prevalence of HCV were made possible in 1989 by discovery of the virus and subsequent generation of anti-HCV markers. ${ }^{2}$ The first generation enzyme-linked

Address for correspondence and reprint requests: Jack R. Wands, M.D., Director, Division of Gastroenterology and The Liver Research Center, Warren Alpert Medical School of Brown University, 55 Claverick Street, 4th Floor, Providence, RI 02903 (jack_wands_md@brown.edu). 
immunoabsorbance (EIA1) assay utilized antibodies against antigen C-100 derived from the nonstructural protein 4 (NS4). ${ }^{3}$ The earliest epidemiologic studies using EIA1 for screening showed increased HCV seropositivity rates of 2.3 to $76 \%$ in alcholic patients. ${ }^{4-13}$

Subsequently, a second screening immunoabsorbance test detecting antibodies to recombinant antigens from the core (C22) and nonstructural regions 3 (C33) and 4 (C100) of the HCV was developed in 1992 and was shown to be more specific compared with the EIA1 assay. ${ }^{3}$ It is conceivable that early studies using the less-specific EIA led to falsely inflated rates of HCV in alcoholic patients; however, further studies utilizing EIA2 as the substrate also produced comparable results of $\mathrm{HCV}$ in alcoholic patients of 1,2 to $55 \% .{ }^{14-21} \mathrm{~A}$ third-generation anti$\mathrm{HCV}$ assay was later developed. (EIA), containing reconfigured core and nonstructural (NS3) proteins, and addition of the NS5 antigen was shown to be superior in sensitivity and specificity as compared with prior anti-HCV assays. ${ }^{22}$ Several prevalence studies using EIA3, however, continued to reveal high association rates between alcohol abuse and chronic HCV infection of 4.4 to $31.2 \% .^{23-27}$

Taken together, the majority of studies have shown that alcoholics have an increased prevalence of HCV as compared with nonalcoholics either within the study or as compared with the global prevalence of $2.2 \%{ }^{28}$ The reason for this statistical association has not been elucidated; moreover, many chronic alcoholics have been shown to be polysubstance abusers with parental risk factors, increasing their chance for exposure and development of chronic HCV infection.

${ }^{24}$ Furthermore, there have been conflicting studies that show the increased prevalence of HCV in alcoholics is related to history of intravenous drug use (IVDU). Nyamathi et al controlled for patients without history of IVDU and showed prevalence of HCV in homeless alcoholics and nonalcoholics to be $19.4 \%$ and $9.4 \%$, respectively. ${ }^{29}$ Rosman et al also compared anti$\mathrm{HCV}$ positive rates among non-IV drug users in 87 alcoholic patients undergoing detoxification, 33 alcoholic and 77 nonalcoholic patients and revealed positive rates of 10.3, $3.0,0 \%$, respectively. ${ }^{18}$ These investigations suggest the presence of unidentified transmission associated factors among alcoholics that increase their risks for HCV. Finally, there is a direct relationship between chronic $\mathrm{HCV}$ infection and liver disease severity in alcoholics. As shown in Fig. 1, alcoholics without liver disease in several studies have HCV prevalence rates of 1.1 to $10 \%$, whereas those with cirrhosis have rates of 10.5 to $44.4 \%$ and in $\mathrm{HCC}$ it varies from 12.5 to $100 \%$ depending on the series. This epidemiologic pattern is suggestive of a synergistic effect between alcohol and HCV in liver disease progression.

However, it is important to weigh the effects of selection bias in considering the increased rate of $\mathrm{HCV}$ in alcoholics. Most studies have been performed with inpatient or detoxifying alcoholic populations, who presumably have higher rates of $\mathrm{HCV}$, because of complications arising from advanced liver disease or comorbidities arising from such diseases. Few outpatient or general population studies, on the other hand, have revealed comparably low rates of $\mathrm{HCV}$ ranging from 1.2 to $4.4 \% .^{15,18,19,23}$ Indeed, Chang et al conducted a study of general outpatient Taiwanese population showing no association with alcoholism and HCV rates. ${ }^{15}$ The observation that inpatient or detoxifying alcoholics have much higher rates of chronic $\mathrm{HCV}$ infection may be explained, in part, by the inpatient setting where presentation with advanced liver disease (as can be accelerated by HCV coinfection) and/or complications from liver disease is more common. The gold standard at present is measurement of $\mathrm{HCV}$ ribonucleic acid (RNA) in serum by real-time reverse transcriptase-polymerase chain reaction (RT-PCR), which has a sensitivity of $\sim 50$ viral copies $/ \mathrm{mL}$. Therefore, prevalence rates in alcoholic populations should be revisited using ultra-sensitive assays for viral detection in blood.

\section{PATHOGENESIS}

Although alcohol and HCV are both independent risk factors for hepatocytic damage with different histologic and gene expression patterns, ${ }^{30,31}$ there is substantial evidence to show 
that the two effectors combine synergistically to damage the liver. Alcoholics with HCV have been observed to have faster rates of fibrosis progression with more rapid and frequent occurrence of cirrhosis compared with nondrinkers. ${ }^{32}$ In an attempt to clarify this phenomenon, Hutchinson et al performed a meta-analysis of 20 studies involving $>15,000$ patients demonstrating that heavy drinking (210 to $560 \mathrm{~g} / \mathrm{wk}$ ) increased the risk of advanced fibrosis, cirrhosis, and decompensated cirrhosis. ${ }^{33}$ Wiley et al compared and measured liver fibrosis progression between $90 \mathrm{HCV}$-positive alcoholics and $86 \mathrm{HCV}$-positive nonalcoholics and revealed that the first group progressed one fibrosis score every 7 years as compared with 1 score per 14 years, respectively. ${ }^{34}$ The synergistic or additive effects and mechanisms by which alcohol worsens HCV-related liver disease have not been clarified, but impairment of immune response, enhanced viral replication, increased oxidative stress, and hepatocyte cytotoxicity have been postulated as major factors in liver disease progression. A representative example of the type of liver disease often observed in chronic HCV-infected individuals with alcoholinduced hepatic injury is depicted in Fig. 2. This liver biopsy shows histologic evidence of injury by both agents as characterized by periportal infiltration of lymphocytes, micro- and macrosteatosis, lobular disarray, cell drop out, presence of acute inflammatory cells, and fibrosis.

Upregulated programmed cell death pathways (apoptosis) has been described in HCV-infected hepatocytes. ${ }^{35,36}$ It is generally believed that enhanced apoptosis is not a direct cytotoxic effect of HCV, but rather due to the host's immune response required for viral clearance. ${ }^{35,36}$ Apoptosis is mediated through cytotoxic T lymphocytes and natural killer cells, and cell death is performed with the help of caspases. Bcl-2 protein, a proto-oncogene located on chromosome 18 , is known to suppress apoptosis by preventing activation of these caspases ${ }^{36}$ and appears to be underexpressed in HCV-infected hepatocytes. ${ }^{37}$ There has been evidence to show that alcohol exposure to $\mathrm{HCV}$-infected hepatocytes synergistically enhances apoptosis. In one study of $20 \mathrm{HCV}$-infected patients with variable alcohol use, higher levels of apoptosis were seen in liver tissue of HCV patients consuming) $\geq 30 \mathrm{~g} / \mathrm{d}$ versus those consuming $<10 \mathrm{~g} / \mathrm{d} .{ }^{38}$ In this study, heavy alcohol intake was associated with the highest rates of apoptosis with undetectable levels of Bcl-2 protein in hepatocytes. ${ }^{38}$ The authors concluded that alcohol further downregulated Bcl-2 expression, causing increased apoptosis and more severe liver injury.

Lipid peroxidation, with release of free radicals and reactive oxygen species (ROS), and attenuation of antioxidative defense mechanisms (namely, depletion of hepatic glutathione) contributes to the progression of both $\mathrm{ALD}^{39}$ and $\mathrm{HCV}$ infection independently ${ }^{40}$ and additively. ${ }^{22,41}$ In $\mathrm{HCV}$-induced oxidative stress, the main viral molecule that has been implicated in these effects is the core protein, which is a key structural component of the nucleocapsid. ${ }^{40}$ The HCV core protein binds to the mitochondrial outer membrane at the junction with the endoplasmic reticulum to facilitate influx of calcium into the mitochondrial matrix, stimulating electron transport and a subsequent increase in the generation of ROS. ${ }^{42}$ When this process exceeds the antioxidant capacity of the hepatocyte, there is depletion of glutathione (GSH) and accumulation of glutathione disulfide.

In ethanol-induced oxidative injury, cytochrome P450 2E1 (CYP2E1) has been implicated in the increased production of ROS and enhanced GSH oxidation, which ultimately results in mitochondrial injury. ${ }^{42}$ Alcohol dehydrogenase and CYP2E1-dependent metabolism of alcohol both produce a stable product of acetaldehyde; however, CYP2E1 does so through a separate pathway using oxygen to metabolize alcohol. In this catabolic pathway of alcohol metabolism, electron transfer from alcohol to oxygen bound to heme groups can essentially form superoxide molecules that may be released in the process. As a result of generating ROS, CYP2E1 also can indirectly catalyze the formation of a free radical species from ethanol itself [1-(hydroxyethyl)], which further contributes to oxidative damage. ${ }^{43}$ In addition, CYP2E1 
appears to be substantially "uncoupled" compared with other P450s, meaning that it generates ROS and oxidative stress far more readily than other enzymes of this family.

Given the separate pathways that result in a common outcome of oxidative stress, the potential for additive or synergistic effects by these two hepatotoxic insults should be recognized. There has been accumulating evidence to support the oxidative stress theory of alcohol and HCV synergism with respect to adverse effects on the liver. In one study, alcohol markedly increased the phosphatidylcholine hydroperoxides $(\mathrm{PCOOH})$ level in $\mathrm{HCV}$ transgenic mice, suggesting synergism between alcohol and $\mathrm{HCV}$ in promoting hepatocarcinogenesis. Compared with nontransgenic controls mice fed a 5\% ethanol diet for 3 weeks demonstrated a small increase in PCOOH levels. However, alcohol consuming HCV transgenic mice exhibited a 2-fold increase in $\mathrm{PCOOH}$ levels compared with nontransgenic controls fed the same 5\% ethanol diet or transgenic mice not fed an ethanol diet. ${ }^{44}$

Other studies reveal that HCV core-transgenic mice fed alcohol-containing diets displayed preferential activation of extracellular regulated kinase (ERK) and p38 mitogen activated protein kinase (MAPK) - both of which have been shown to be important components related to increased oxidative stress. ${ }^{45}$ In addition, the three most attenuated genes found in this study - metallothionein, glutathione S-transferase- (GST-) M1B, and GST-P1 - are known to be potent oxygen radical scavengers and detoxification enzymes involved in conjugation of GSH, respectively. ${ }^{45}$ Otani et al found that mitochondrial ROS production is induced by HCV core and CYP2E1, resulting in a reduction of mitochondrial antioxidant capacity and sensitivity to oxidants and tumor necrosis factor- $\alpha(\mathrm{TNF} \alpha)$. Alcohol further depletes mitochondrial reduced $\mathrm{GSH}$, which promotes depolarization and cell death. Sensitization of mitochondria to oxidative insults is thus a potential mechanism for alcohol-related exacerbation of liver injury in persons with chronic $\mathrm{HCV} .{ }^{46}$ There is in vivo evidence of increased oxidative stress as the mechanism of synergy between alcohol and $\mathrm{HCV}$ in advanced liver damage. One study found that the risk of developing oxidative stress during chronic $\mathrm{HCV}$ infection was increased 3-fold by moderate and 13- to 24-fold by heavy alcohol consumption, and was associated with increased piecemeal necrosis and fibrosis among chronic alcoholics in comparision to abstainers. ${ }^{41}$ Similarly, a recent investigation by Castellano-Higuera et al revealed more in vivo evidence of oxidative damage synergism between alcohol and HCV. It was found that malondialdehyde (MDA - a product of lipid peroxidation) levels and glutathione peroxidase activity were both increased, further supporting the role of oxidative damage to the liver with alcoholism and chronic HCV infection. ${ }^{47}$ Thus, there are multiple molecular mechanisms involved in the acute and chronic liver injury produced by persistent HCV infection in the context of chronic alcohol abuse.

\section{IMMUNE RESPONSE}

Although it has been established that chronic alcoholics have a high incidence of HCV infection, 1,48 the reasons for these high rates are unknown but may partially relate to the effects of alcohol on the humoral and cellular immune responses to viral structural and nonstructural proteins. To test this hypothesis in an animal model system, HCV core DNA constructs were generated to access viral specific antibody and cellular immune responses following genetic immunization. ${ }^{49-52}$ Transient expression of HCV proteins encoded by plasmids in muscle cells or fibroblasts followed by activation of DCs at the site of immunization or in adjacent draining lymph nodes seemed to the most probable mechanism for induction of antiviral immune responses. However, chronic alcohol feeding had a profound inhibitory effect on cellular immune responses such as the generation of antigen specific CD4+ and CD8+ T cell activity using HCV core as the immunogen. The inhibitory effect of alcohol could be partially or completely compensated by coimmunization with an interleukin- 2 or granulocyte macrophage colony-stimulating factor (GM-CSF) expression plasmid, respectively. These experiments reveal that DNA-based immunization was enhanced by cytokine production at 
the site of antigen presentation and that antigen presenting cells (APCs) may be a cellular target during chronic alcohol consumption. ${ }^{49,53-55}$

Such investigations were extended to HCV nonstructural proteins such as NS5: human data suggests that CD4+ and CD8+ $\mathrm{T}$ cell activity directed against epitopes that reside on nonstructural proteins are important in viral clearance during the natural resolution of $\mathrm{HCV}$ infection. ${ }^{56}$ It has been observed that immunization with an NS5 gene-containing DNA induced a brisk antibody response, promoted CD4+ T cell proliferation and Th1 cytokine release, and generated cytotoxic T lymphocyte (CTL) activity. ${ }^{49}$ More important, there was substantial inhibition of NS5 specific CD4+ and CD8+ T cell activity that was only partially restored followed cessation of chronic alcohol consumption. ${ }^{53}$ Because alcohol's suppressive effect on CTL activity was reversed by coimmunization with a plasmid encoding for GM-CSF, it has been hypothesized that one major effect of alcohol on antiviral immune responses might be at the level of antigen presentation. These studies reveal that DCs differentiated in vivo in the context of chronic alcohol feeding have intrinsic functional defects, which may explain, in large part, the depressed CTL activity previously observed after DNA-based immunization using HCV core and NS5 as the immunogens. ${ }^{49,53,57-59}$

There is substantial evidence that heavy alcohol consumption has other adverse effects on the immune system. ${ }^{60-68}$ For example, there are reduced CD $4+\mathrm{T}$ cell proliferative responses as well as alterations in delayed hypersensitivity reactions. ${ }^{69-71}$ These abnormalities have been associated with an increased incidence of viral and bacterial infections. ${ }^{34,60,72}$ Only recently has there been evidence that chronic alcohol exposure affects human monocytes and monocytederived DCs. ${ }^{73-75}$ The molecular mechanisms of how alcohol cause an immune-compromised state is poorly understood and is of considerable clinical importance because microbial infections are a major medical problem in alcoholics. Even less is known regarding the alteration in cellular immune responses that may predispose to persistent HCV infection in alcoholics. The interplay of alcohol, HCV, and the host immune response has only recently been investigated in animal models. ${ }^{52,53}$ There are multiple effects of alcohol on modulation of the humoral and cellular immune responses that involve the activities of neutrophils, monocytes, and lymphocytes. ${ }^{68}$

In this regard, DCs play a crucial role in generating immune responses to viral proteins. Dendritic cells are highly specialized APCs. They are characterized by their ability to take up, process, and present antigen to effector T cells. DCs act at the interface of innate and adaptive immune response. According to the environmental circumstances, they can function diametrically. They either elicit an adaptive immune response or a tolerogenic reaction to the antigen they present. For the successful initiation of an adaptive immune response, DCs need to express costimulatory molecules on their surface. ${ }^{76,77}$ Their upregulation is mediated by several factors such as toll-like receptor-ligand interactions or binding to CD40 by the CD40 ligand. Through the latter, the interaction of DCs and T cells is sustained and the antigen presentation efficiency increased. ${ }^{78}$ The capability of DCs to elicit robust immune responses makes them appealing for immune-modulatory strategies. Beyond numerous approaches in laboratory-based studies, several clinical trials have been conducted in which DCs were used as carriers for tumor associated proteins, particularly in cancer therapies. ${ }^{79-81}$ Indeed, DCbased immunization was recently shown to be a suitable approach to elicit sustained immune responses to $\mathrm{HCV}$ proteins. ${ }^{82,83}$ Like all phagocytic cells, DCs are equipped with antigen uptake mediating receptors, including members of the $\mathrm{C}$-type lectin receptors. The phagocytic process is initiated through the calcium-dependent binding of C-type lectins to carbohydratebearing pathogen-derived antigens using highly conserved corbohydrate recognition domains. Some of these receptors appear ubiquitously on phagocytic cells, such as macrophages, monocytes, B-lymphocytes, neutrophils, and DCs. ${ }^{84}$ 
There are three major DC populations in mice: myeloid (CD11c+, CD11b+), lymphoid (CD11c ,$+ \mathrm{CD} 8+$ ), and plasmacytoid (CD11c+, B220+). ${ }^{85,86}$ Although there is considerable debate regarding the function of each subpopulation, it appears that myeloid DCs are more often implicated in the generation of Th2 responses, where lymphoid and plasmacytoid DCs are likely to direct the immune response toward a Th1-type activity necessary for viral clearance of infected cells ${ }^{87}$ as shown in Fig. 3. One emerging hypothesis is that altered DC functions is one of the major immunologic changes produced by alcohol and there may be differential effects on DC subpopulations, which subsequently impairs the cellular immune response necessary for viral clearance. ${ }^{42,57,73,88-91}$ Therefore, it would be of interest to develop and implement strategies in animal models that increase the ability of the alcohol-consuming host to generate better antiviral responses.

To understand alcohol's effects on the immune response to HCV, it is necessary to take advantage of the knowledge gained from previous clinical studies on the adaptive host response to acute $\mathrm{HCV}$ infection. Clearance of HCV is associated with an early, multi- specific, strong $\mathrm{CD} 8+$ cell immunity that is matched by a vigorous and sustained CD4+ $\mathrm{T}$ cell proliferation response to multiple structural and nonstructural viral proteins. ${ }^{92-94}$ Activated T-cells secrete proinflammatory cytokines (Th1-type) such as interferon $\gamma($ IFN- $\gamma$ ) coinciding with large reductions in viral load during acute infection ${ }^{94}$ and paralleled by direct antiviral activity for $\mathrm{HCV}$ replicons in culture. ${ }^{95}$ Importantly, the accumulation of IFN- $\gamma$ secreting CD4+ and CD8 + cells occurs in the liver. ${ }^{96} \mathrm{HCV}$ infections that are successfully controlled result in memory populations. ${ }^{97}$ This observation is supported by a substantially lower rate of HCV persistance in reexposed humans with a history of acute resolving HCV. ${ }^{98}$ Rechallenge experiments in chimpanzees showed that antibody-mediated depletion of CD4+ T-cells resulted in HCV persistence in contrast to marked reduction in duration and peak of viremia found in nontreated animals. ${ }^{99,100}$ The importance of CD4+ T-cells in further emphasized by the loss of immune protection correlating with low CD4+ positive counts, against reexposure to $\mathrm{HCV}$ by intravenous drug abusers who had recovered from $\mathrm{HCV}$, but subsequently acquired an human immunodeficiency virus (HIV) infection. ${ }^{98}$ Whether recovery from acute $\mathrm{HCV}$ coincides ultimately with virus eradication is still a matter of debate. ${ }^{101}$ Disappearance of $\mathrm{HCV}$-specific antibodies in some individuals 10 to 20 years after viral clearance indicates that a subgroup of patients achieves final virus elimination. ${ }^{102}$ Persistent HCV infection correlates with defects in the effector level of adaptive immunity, with permanent loss of HCV-specific T-cell proliferation during acute $\mathrm{HCV}$ and functional exhaustion of an initially vigorous response, such as the inability of effector $\mathrm{T}$ cells to migrate into the infected liver. $82,92,93,96,103,104$ Insufficient CD4+ T-cell activity appears to be a key event leading to chronic HCV infection because failure to sustain the CD4+ helper response renders virus-specific CD8+ T-cells inadequate (e.g., loss of cytotoxicity and IFN- $\gamma$ production) contributing to persistent viremia. 104

The central concept of altered DC function as a key mechanism for impaired antiviral immune responses generated by chronic alcohol consumption has gained considerable experimental support. Access to sufficient quantities of mature DCs is a critical issue as only these cells are capable of targeting the antigen and inducing cellular immunity rather than tolerance. It is now possible to generate large numbers of DCs in vivo. ${ }^{57,83}$ These, in turn, may be enriched in vitro by phagocytosis of magnetic microparticles and separated in a magnetic field. By inoculating mice with microbeads coated with the nonstructural HCV antigen NS5 and compounds known to induce DC maturation, significant levels of cellular and humoral immunity of the type required for resolution of this viral infection are elicited. The attractive elements of this approach reside in the combined enrichment, maturation, and antigen targeting of DCs in a single step, thus avoiding elaborate culturing conditions that influence the generation of cellular phenotypes in vitro. 57,105 
Murine models have been employed to study the effects of chronic alcohol consumption on DC function generated in vivo under controlled conditions. This approach allowed investigation of alcohol's effect on DCs with respect to cell surface markers, cytokine profiles, antigen presentation ability, and endocytosis capacity. Furthermore, the subsequent role of DC dys-function in the generation of CTL immune responses has been evaluated following genetic immunization with a plasmid expressing NS5 protein by using adoptive transfer of syngeneic DCs. In vivo generation of DCs combined with syngeneic DC transfer and DNA-based immunization, revealed that alcohol-induced dysfunction of DCs adversely impacts the host response to $\mathrm{HCV} .{ }^{57}$ This finding may have relevance to persistent $\mathrm{HCV}$ infection in alcoholics Thus, DCs represent one of the major cellular targets in the immune system for chronic alcohol effects and impair the generation of CD8+, CTL, and CD4+ proliferative activity' to viral structural and nonstructural proteins that may be required for viral resolution. ${ }^{57,74,75,83,106}$ Such preclinical investigations open avenues to enhance antiviral immune responses in the setting of chronic alcohol consumption by improving DC function.

\section{THERAPY}

The mechanism by which alcohol exacerbates liver damage caused by HCV infection remains incompletely understood Numerous studies have demonstrated that alcohol consumption in varied quantities can enhance viral replication, increase oxidative stress, worsen cytotoxicity, and impair immune response. Consequently, alcohol abuse appears to reduce both sensitivity to interferon and adherence to treatment. Given the large number of individuals both infected by $\mathrm{HCV}$ and afflicted by alcohol dependence, further understanding of treatment efficacy in this population is essential.

Alcohol abuse has been shown to reduce response rates to IFN therapy in patients with chronic $\mathrm{HCV}$. Thus, effects of alcohol on this cellular pathway have been explored. IFN- $\gamma$ induces transcription of genes that mediate antiviral responses. These genes are activated via a series of phosphorylation events involving tyrosine kinase receptors Tyk2 and JakI, and STAT1 and STAT2, with stimulation of IFN $\alpha$ induced genes. Plumlee et al ${ }^{107}$ were able to show that ethanol inhibited STAT1 tyrosine phosphorylation necessary for IFN gene induction in Huh 7 hepatoma cells, HCV replicon containing cell lines and human hepatocytes. This mechanism may be responsible for the reduced response to IFN observed in some studies of alcoholics with HCV infection.

The effect of alcohol on HCV replication has been examined in several investigations yielding inconsistent results. For example, Anand et al performed a meta-analysis involving 14 studies, assessing the effect of alcohol on HCV titers based on (1) a comparison of heaviest drinkers versus nondrinkers, (2) effects of graded doses of alcohol (abstainers, moderate alcohol users, and heavy drinkers), and (3) abstinence in the same individual. The conclusion was that no difference in viral titers between alcoholics and nondrinkers exist with respect to these three clinical paradigms. ${ }^{108}$ However, the authors acknowledge the limitations of this meta-analysis because there were no uniform criteria for the definition of alcoholism as well as standardization of techniques used to measure HCV levels. Additionally, Singal et al reports that viral serum titers may not be a reliable gauge of true intrahepatic replicative activity. Therefore, there is an inconsistent relationship between serum- and liver-derived viral levels and evidence was provided to support the use of peripheral blood mononuclear cells as a better index of viral titers in future studies. ${ }^{32}$

Traditional therapy for $\mathrm{HCV}$ infection is tailored to the individual based on viral genotype and treatment response. Numerous trials have been conducted to address the appropriate therapy and treatment duration for individuals based on variables including genotype, weight, ethnicity, rapid/early virologic response, and the presence of comorbid conditions. ${ }^{109,110}$ Although both 
medication dosages and duration of therapy have been modified in different populations in efforts to increase the incidence of sustained virologic response (SVR), there remains little information on the optimal treatment for alcoholics. In the past, substance abuse including alcohol was considered a contraindication to treatment. ${ }^{111}$ Consequently, data on treatment efficacy in this subgroup remains limited.

Combination therapy with IFN and ribavirin has markedly increased SVR in all genotypes over that of IFN alone. Currently, the majority of available studies that examine treatment response among drinkers only employ monotherapy with IFN. Overall, response rates appear to be dramatically lower and relapse rates higher among individuals who consume substantial amounts of alcohol prior to or during treatment. A study conducted by Okazaki et al ${ }^{112}$ to further evaluate response rates among those considered heavy, light, and nondrinkers revealed significant differences between groups. Treatment response was diminished as alcohol intake increased. Although other researchers have demonstrated a posttreatment improvement in liver histology, this study shows that IFN afforded no histologic improvement among light and heavy drinkers. ${ }^{112,113}$ This finding suggests that, not only are these individuals less responsive to therapy, but that they are also more resistant to other beneficial aspects of treatment such as inflammation reduction and reversal of fibrosis.

It has been well documented that high pretreatment viral loads correlate to decreased SVR. ${ }^{114}$ In 1994, Oshita et al investigated the effect of alcohol intake on the replication of HCV and the efficacy of interferon therapy. Their cohort of 53 patients was divided into those characterized as habitual drinkers and nonhabitual drinkers. After a 26-week course of IFN $\alpha$ therapy, viral RNA titers among habitual drinkers was significantly, higher than that in nonhabitual drinkers. Neopterin levels in serum, as a marker for the activation of cell-mediated immunity, were markedly lower for habitual than for nonhabitual drinkers. In addition, the number of persons experiencing long-term response was significantly lower among habitual drinkers. These findings suggest that alcohol intake increases HCV RNA levels in serum, impairs cellular immunity, and modulates the efficacy of IFN therapy.

A multicenter trial later conducted by Loguercio et al has also demonstrated that HCV RNA levels are significantly higher among drinkers when compared with matched abstainers. As would be expected, this research shows that response rates were inversely proportional to alcohol consumption. ${ }^{115}$ Thus, the percentage of responders decreased with increased alcohol intake. The group with the highest measured alcohol intake $(>80 \mathrm{~g} / \mathrm{d})$ had the highest percentage of nonresponders.

In accordance with these studies, Ohnishi et al ${ }^{116}$ shows decreased treatment efficacy with increased alcohol consumption. These results also suggest the same inverse relationship between incrementally increased alcohol intake and decreased treatment response. Unlike studies conducted by Okazaki et al and Oshita et al, this research demonstrates that the adverse effect of habitual heavy drinking on the efficacy of IFN therapy might be reversed, at least in part, by abstinence for more than 6 months prior to initiation of therapy. In addition, Ohnishi et al demonstrates that there was no significant difference in treatment efficacy between infrequent and habitual drinkers who consumed more than $23 \mathrm{~g}$, but less than $69 \mathrm{~g}$ of alcohol daily, and who had stopped drinking for a minimum of 6 months (average of 39 months prior to treatment).

Heavy drinkers ( $>69 \mathrm{gm} / \mathrm{d}$ ), however, who abstained for more than 6 months prior to treatment had a statistically significant rise in treatment response when compared with heavy drinkers who did not observe comparable abstinence. This suggests that the detrimental effects of excessive alcohol on treatment efficacy may be, at least in put, reversible. It is possible that this finding results from a return of immune function following detoxification, which is 
supported by preclinical studies in mice. The resultant drop in HCV RNA levels among heavy drinkers during periods of abstinence may also play a role in increasing treatment efficacy.

In addition to current alcohol use, total lifetime alcohol intake appears to influence the effectiveness of therapy. Tabone et al ${ }^{117}$ examined response rates among HCV-infected individuals in the context of lifetime alcohol use Here, all patients were committed to a 6month period of abstinence prior to the initiation of IFN therapy. The sustained virologic response rate fell from $33 \%$ in nondrinkers to $20 \%$ in mild drinkers and to only $9 \%$ in heavy drinkers. Drinkers also showed a relapse rate twice as high as that of nondrinkers. According to their multivariate analysis, the strongest independent predictors of nonresponse were genotype $1 \mathrm{~b}$ infection, age of the patients, and their lifetime alcohol intake. Lifetime alcohol consumption proved to have a strong negative effect on the outcome of interferon treatment, specifically in heavy drinkers. These authors concluded that a 6-month period of abstinence may not be sufficient to offset this negative effect on treatment outcome. This finding also suggests the possibility that alcohol in large quantities over a significant time period may irreversibly impact treatment response. Increased fibrosis and fat deposition, only minimally changed by long periods of abstinence, may play a role. To date, the impact of lengthier period of abstinence on treatment outcomes has not been explored.

Pretreatment liver histology has also been reported to affect the response to IFN therapy. It is generally accepted that the response to IFN therapy worsens with histologically advanced stages of liver disease as evaluated by Knodell's fibrosis score. Ohnishi et al ${ }^{116}$ demonstrated a lesser response to IFN therapy in patients with a fibrosis score of 3 compared with those with fibrosis scores of 1 or 2, both in infrequent and habitual drinkers. Further, this research shows that treatment efficacy was less in habitual drinkers than in infrequent drinkers even when comparing those with similar fibrosis scores. These observations suggest that factors beyond alcohol-induced fibrosis plays a pivotal role in treatment response. Ohnishi et al thus compared fat deposition, perivenular fibrosis, and stellate fibrosis between groups. Such measures of liver damage were significantly more prominent in the two heavy drinkers' groups when compared with infrequent drinkers. Interestingly, pericellular fibrosis was more severe among heavy drinkers who did not observe pretreatment abstinence of 6 or more months prior to treatment. These findings suggest that histologic changes in the liver produced by habitual drinking and improved by abstinence might have contributed to the poor treatment response. ${ }^{117}$

Another variable that may have a negative impact on treatment response is the existence of viral quasispecies. Habitual drinking suppresses the innate immunological response to HCV infection. In turn, mutation in the HCV genome could easily occur, resulting in an increased viral diversity and increased resistance to IFN therapy. Kanazawa et al ${ }^{118}$ studied the heterogeneity of the hypervariable regions in the HCV in patients treated with IFN $\alpha$ to clarify the implications of quasispecies. This group sequenced recombinant clones generated from PCR-amplified products of the hypervariable regions. The sets of clones derived from longterm responders before IFN therapy showed a significantly lower degree of sequence complexity of the hypervariable region 1 quasispecies than those from short-term responders or nonresponders. The degree of nucleotide diversity, or the average number of nucleotide differences per site between two randomly chosen sequences, in hypervariable region 1 before IFN therapy were also significantly lower for long-term responders. Consequently, the degree of quasispecies' complexity and diversity of hypervariable region 1 was closely correlated with the responsiveness to IFN therapy. Thus, increased viral sequence heterogeneity that develops in alcoholics may negatively influence treatment outcomes. 


\section{PERSPECTIVES}

There is a clear need to study further the interaction of alcohol and HCV in both the clinical setting and preclinical animal models. More information is required on the role and mechanisms of oxidative stress generation and apoptosis of hepatocytes in alcoholics with chronic HCV infection. Because the immune response appears to be substantially blunted in alcoholics, it will be important to clarify the cellular targets of ethanol action as a mechanism for depressed viral specific CD4+ and CD8+ immunity. Because DCs appear to be important in the pathogenesis of this abnormal immune response, investigations regarding subpopulations both in the peripheral blood and in the liver need to be carefully assessed. Additional studies are required to develop an optimal regimen and dosage of IFN $\alpha$ and ribavirin in alcoholics with $\mathrm{HCV}$ in an attempt to generate better sustained virologic responses. The effect of abstinence on treatment response needs clarification, and molecular studies detailing the formation of HCV quasispecies in alcoholics with respect to the efficacy' of treatment should be explored. Finally, additional investigations on the role of both alcohol and HCV infection on progression of liver injury through fibrosis to hepatocellular carcinoma at the molecular level is needed.

\section{Acknowledgments}

Supported in part by NIH Grants NIAAA RO1-AA002666 and -AA008169 (J.R.W.).

\section{ABBREVIATIONS}

$\begin{array}{ll}\text { APC } & \text { antigen presenting cell } \\ \text { CD4+ } & \text { cluster of differentiation } 4 \\ \text { CD8+ } & \text { cluster of differentiation } 8 \\ \text { CTL } & \text { cytotoxic T lymphocyte } \\ \text { CYP2E1 } & \text { cytochrome P450 2E1 } \\ \text { DC } & \text { dendritic cell } \\ \text { EIA } & \text { enzyme-linked immunoabsorbance } \\ \text { ERK } & \text { extracellular regulated kinase } \\ \text { GM-CSF } & \text { granulocyte macrophage colony-stimulating factor } \\ \text { GSH } & \text { glutathione } \\ \text { GST } & \text { glutathione S transferase } \\ \text { HCC } & \text { hepatocellular carcinoma } \\ \text { HCV } & \text { hepatitis C virus } \\ \text { IFN } & \text { interferon } \\ \text { IVDU } & \text { intravenous drug use } \\ \text { MAPK } & \text { mitogen activated protein kinase } \\ \text { NS3 } & \text { nonstructural protein 3 } \\ \text { NS4 } & \text { nonstructural protein 4 } \\ \text { PCOOH } & \text { reactive oxygen species } \\ \text { RNA } & \text { ROS }\end{array}$


RT-PCR reverse transcriptase-polymerase chain reaction

SVR

sustained virologic response

\section{References}

1. Schiff ER, Ozden N. Hepatitis C and alcohol. Alcohol Res Health 2003;27:232-239. [PubMed: 15535451]

2. Kuo G, Choo QL, Alter HJ, et al. An assay for circulating antibodies to major etiologic virus of human non-A, non-B hepatitis. Science 1989;244:362-364. [PubMed: 2496467]

3. Gretch DR. Diagnostic tests for hepatitis C. Hepatology 1997;26:43S-47S. [PubMed: 9305663]

4. Bode JC, Biermann J, Kohse KP, Walker S, Bode C. High incidence of antibodies to hepatitis C virus in alcoholic cirrhosis: fact or fiction? Alcohol Alcohol 1991;26:111-114. [PubMed: 1652249]

5. Brillanti S, Masci C, Siringo S, Di Febo G, Miglioli M, Barbara L. Serological and histological aspects of hepatitis C virus infection in alcoholic patients. J Hepatol 1991;13:347-350. [PubMed: 1667017]

6. Bruix J, Barrera JM, Calvet X, et al. Prevalence of antibodies to hepatitis C virus in Spanish patients with hepatocellular carcinoma and hepatic cirrhosis. Lancet 1989;2:1004-1006. [PubMed: 2572739]

7. Caldwell SH, Li X, Rourk RM, et al. Hepatitis C infection by polymerase chain reaction in alcoholics: false-positive ELISA results and the influence of infection on a clinical prognostic score. Am J Gastroenterol 1993;88:1016-1021. [PubMed: 8391209]

8. Chang TT, Lin CY, Chow NH, et al. Hepatitis B and hepatitis C virus infection among chronic alcoholic patients with liver disease in Taiwan. J Formos Med Assoc 1994;93:128-133. [PubMed: 7912583]

9. Mendenhall CL, Seeff L, Diehl AM, et al. Antibodies to hepatitis B virus and hepatitis C virus in alcoholic hepatitis and cirrhosis: their prevalence and clinical relevance. The VA Cooperative Study Group (No. 119). Hepatology 1991;14:581-589. [PubMed: 1655605]

10. Nishiguchi S, Kuroki T, Yabusako T, et al. Detection of hepatitis C virus antibodies and hepatitis C virus RNA in patients with alcoholic liver disease. Hepatology 1991;14:985-989. [PubMed: 1660025]

11. Pares A, Barrera JM, Caballeria J, et al. Hepatitis C virus antibodies in chronic alcoholic patients: association with severity of liver injury. Hepatology 1990;12:1295-1299. [PubMed: 2175291]

12. Shimizu S, Kiyosawa K, Sodeyama T, Tanaka E, Nakano M. High prevalence of antibody to hepatitis C virus in heavy drinkers with chronic liver diseases in Japan. J Gastroenterol Hepatol 1992;7:3035. [PubMed: 1311967]

13. Zarski JP, Thelu MA, Moulin C, Rachail M, Seigneurin JM. Interest of the detection of hepatitis C virus RNA in patients with alcoholic liver disease. Comparison with the HBV status. J Hepatol 1993;17:10-14. [PubMed: 7680361]

14. Befrits R, Hedman M, Blomquist L, et al. Chronic hepatitis C in alcoholic patients: prevalence, genotypes, and correlation to liver disease. Scand J Gastroenterol 1995;30:1113-1118. [PubMed: 8578173]

15. Chang HC, Yu MW, Lu CF, Chiu YH, Chen CJ. Risk factors associated with hepatitis C virus infection in Taiwanese government employees. Epidemiol Infect 2001;126:291-299. [PubMed: 11349980]

16. Coelho-Little ME, Jeffers LJ, Bernstein DE, et al. Hepatitis C virus in alcoholic patients with and without clinically apparent liver disease. Alcohol Clin Exp Res 1995;19:1173-1176. [PubMed: 8561287]

17. Gonzalez Quintela A, Alende R, Aguilera A, et al. Hepatitis C virus antibodies in alcoholic patients. Rev Clin Esp 1995;195:367-372. [PubMed: 7644783]

18. Rosman AS, Waraich A, Galvin K, Casiano J, Paronetto F, Lieber CS. Alcoholism is associated with hepatitis C but not hepatitis B in an urban population. Am J Gastroenterol 1996;91:498-505. [PubMed: 8633498]

19. Santos A, Carvalho A, Bento D, et al. Epidemiology of hepatitis C in central Portugal. Prevalence of anti-HCV in the population of the Coimbra District. Acta Med Port 1994;7(Suppl 1):S3-S8.

[PubMed: 7653277] 
20. Sata M, Fukuizumi K, Uchimura Y, et al. Hepatitis C virus infection in patients with clinically diagnosed alcoholic liver diseases. J Viral Hepat 1996;3:143-148. [PubMed: 8871873]

21. Verbaan H, Andersson K, Eriksson S. Intravenous drug abuse-the major route of hepatitis C virus transmission among alcohol-dependent individuals? Scand J Gastrenterol 1993;28:714-718.

22. Perlemuter G, Letteron $P$, Carnot F, et al. Alcohol and hepatitis $C$ virus core protein additively increase lipid peroxidation and synergistically trigger hepatic cytokine expression in a transgenic mouse model. J Hepatol 2003;39:1020-1027. [PubMed: 14642621]

23. Dalgard O, Jeansson S, Skaug K, Raknerud N, Bell H. Hepatitis C in the general adult population of Oslo: Prevalence and clinical spectrum. Scand J Gastroenterol 2003;38:864-870. [PubMed: 12940441]

24. Galperim B, Cheinquer H, Stein A, Fonseca A, Lunge V, Ikuta N. Prevalence of hepatitis C virus in alcoholic: patients: role of parenteral risk factors. Arq Gastroenterol 2006;43:81-84. [PubMed: 17119659]

25. Kwon SY, Ahn MS, Chang HJ. Clinical significance of hepatitis C virus infection to alcoholics with cirrhosis in Korea. J Gastroenterol Hepatol 2000;15:1282-1286. [PubMed: 11129222]

26. Martinez-Raga J, Marshall EJ, Keaney F, Best D, Ball D, Strang J. Hepatitis B and C in alcoholdependent patients admitted to a UK alcohol inpatient treatment unit. Addict Biol 2001;6:363-372. [PubMed: 11900614]

27. Nyamathi AM, Dixon EL, Robbins W, et al. Risk factors for hepatitis C virus infection among homeless adults. J Gen Intern Med 2002;17:134-143. [PubMed: 11841529]

28. Alter MJ. Epidemiology of hepatitis C virus infection. World J Gastroenterol 2007;13:2436-2441. [PubMed: 17552026]

29. Nyamathi A, Robbins WA, Fahey JL, et al. Presence and predictors of hepatitis C virus RNA in the semen of homeless men. Biol Res Nurs 2002;4:22-30. [PubMed: 12363279]

30. Lederer SL, Walters KA, Proll S, et al. Distinct cellular responses differentiating alcohol- and hepatitis C virus-induced liver cirrhosis. Virol J 2006;3:98. [PubMed: 17121680]

31. Uchimura Y, Sata M, Kage M, Abe H, Tanikawa K. A histopathological study of alcoholics with chronic HCV infection: comparison with chronic hepatitis $\mathrm{C}$ and alcoholic liver disease. Liver 1995;15:300-306. [PubMed: 8609809]

32. Singal AK, Anand BS. Mechanisms of synergy between alcohol and hepatitis C virus. J Clin Gastroenterol 2007;41:761-772. [PubMed: 17700425]

33. Hutchinson SJ, Bird SM, Goldberg DJ. Influence of alcohol on the progression of hepatitis $C$ virus infection: a meta-analysis. Clin Gastroenterol Hepatol 2005;3:1150-1159. [PubMed: 16271348]

34. Wiley TE, McCarthy M, Breidi L, McCarthy M, Layden TJ. Impact of alcohol on the histological clinical progression of hepatitis C infection. Hepatology 1998;28:805-809. [PubMed: 9731576]

35. Fischer R, Baumert T, Blum HE. Hepatitis C virus infection and apoptosis. World J Gastroenterol 2007;13:4865-4872. [PubMed: 17828818]

36. Kountouras J, Zavos C, Chatzopoulos D. Apoptosis in hepatitis C. J Viral Hepat 2003;10:335-342. [PubMed: 12969183]

37. Nakamoto Y, Kaneko S, Kobayashi K. Increased susceptibility to apoptosis and attenuated Bcl-2 expression in $\mathrm{T}$ lymphocytes and monocytes from patients with advanced chronic hepatitis $\mathrm{C}$. J Leukoc Biol 2002;72:49-55. [PubMed: 12101262]

38. Pianko S, Patella S, Sievert W. Alcohol consumption induces hepatocyte apoptosis in patients with chronic hepatitis C infection. J Gastroenterol Hepatol 2000;15:798-805. [PubMed: 10937688]

39. Bailey SM, Cunningham CC. Contribution of mitochondria to oxidative stress associated with alcoholic liver disease. Free Radic Biol Med 2002;32:11-16. [PubMed: 11755312]

40. Koike K, Tsutsumi T, Miyoshi H, et al. Molecular basis for the synergy between alcohol and hepatitis C virus in hepatocarcinogenesis. J Gastroenterol Hepatol 2008;23(Suppl 1):S87-S91. [PubMed: 18336672]

41. Rigamonti C, Mottaran E, Reale E, et al. Moderate alcohol consumption increases oxidative stress in patients with chronic hepatitis C. Hepatology 2003;38:42-49. [PubMed: 12829985] 
42. Szabo G, Aloman C, Polyak SJ, Weinman SA, Wands J, Zakhari S. Hepatitis C infection and alcohol use: a dangerous mix for the liver and antiviral immunity. Alcohol Clin Exp Res 2006;30:709-719. [PubMed: 16573590]

43. Koop DR. Alcohol metabolism's damaging effects on the cell: a focus on reactive oxygen generation by the enzyme cytochrome P450 2E1. Alcohol Res Health 2006;29:274-280. [PubMed: 17718406]

44. Moriya K, Nakagawa K, Santa T, et al. Oxidative stress in the absence of inflammation in a mouse model for hepatitis C virus-associated hepatocarcinogenesis. Cancer Res 2001;61:4365-4370. [PubMed: 11389061]

45. Tsutsumi T, Suzuki T, Moriya K, et al. Hepatitis C virus core protein activates ERK and p38 MAPK in cooperation with ethanol in transgenic mice. Hepatology 2003;38:820-828. [PubMed: 14512869]

46. Otani K, Korenaga M, Beard MR, et al. Hepatitis C virus core protein, cytochrome P450 2E1, and alcohol produce combined mitochondrial injury and cytotoxicity in hepatoma cells. Gastroenterology 2005;128:96-107. [PubMed: 15633127]

47. Castellano-Higuera A, Gonzalez-Reimers E, Aleman-Valls MR, et al. Cytokines and lipid peroxidation in alcoholics with chronic hepatitis C virus infection. Alcohol Alcohol 2008;43:137142. [PubMed: 18216180]

48. Oshita M, Hayashi N, Kasahara A, et al. Increased serum hepatitis C virus RNA levels among alcoholic patients with chronic hepatitis C. Hepatology 1994;20:1115-1120. [PubMed: 7523270]

49. Encke J, zu Putlitz J, Geissler M, Wands JR. Genetic immunization generates cellular and humoral immune responses against the nonstructural proteins of the hepatitis $\mathrm{C}$ virus in a murine model. $\mathrm{J}$ Immunol 1998;161:4917-4923. [PubMed: 9794426]

50. Tokushige K, Wakita T, Pachuk C, et al. Expression and immune response to hepatitis $\mathrm{C}$ virus core DNA-based vaccine constructs. Hepatology 1996;24:14-20. [PubMed: 8707253]

51. Stylianou E, Saklatvala J. Interleukin-1. Int J Biochem Cell Biol 1998;30:1075-1079. [PubMed: 9785472]

52. Geissler M, Gesien A, Wands JR. Inhibitory effects of chronic ethanol consumption on cellular immune responses to hepatitis $\mathrm{C}$ virus core protein are reversed by genetic immunizations augmented with cytokine-expressing plasmids. J Immunol 1997;159:5107-5113. [PubMed: 9366440]

53. Encke J, Wands JR. Ethanol inhibition: the humoral and cellular immune response to hepatitis C virus NS5 protein after genetic immunization. Alcohol Clin Exp Res 2000;24:1063-1069. [PubMed: 10924011]

54. Encke J, zu Putlitz J, Wands JR. DNA vaccines. Intervirology 1999;42:117-124. [PubMed: 10516466]

55. Geissler M, Bruss V, Michalak S, et al. Intracellular retention of hepatitis B virus surface proteins reduces interleukin-2 augmentation after genetic immunizations. J Virol 1999;73:4284-4292. [PubMed: 10196326]

56. Rehermann B, Nascimbeni M. Immunology of hepatitis B virus and hepatitis C virus and hepatitis C virus infection. Nat Rev Immunol 2005;5:215-229. [PubMed: 15738952]

57. Aloman C, Gehring S, Wintermeyer P, Kuzushita N, Wands JR. Chronic ethanol consumption impairs cellular immune responses against HCV NS5 protein due to dendritic cell dysfunction. Gastroenterology 2007;132:698-708. [PubMed: 17258730]

58. Geissler M, Gesien A, Tokushige K, Wands JR. Enhancement of cellular and humoral immune responses to hepatitis $\mathrm{C}$ virus core protein using DNA-based vaccines augmented with cytokineexpressing plasmids. J Immunol 1997;158:1231-1237. [PubMed: 9013964]

59. Geissler M, Gesien A, Wands JR. Chronic ethanol effects on cellular immune responses to hepatitis B virus envelope protein: an immunologic mechanism for induction of persistent viral infection in alcoholics. Hepatology 1997;26:761-770.

60. Cook RT. Alcohol abuse, alcoholism, and damage to the immune system - a review. Alcohol Clin Exp Res 1998;22:1927-1942. [PubMed: 9884135]

61. Cook RT, Waldschmidt TJ, Cook BL, Labrecque DR, McLatchie K. Loss of the CD5+ and CD45RAhi B cell subsets in alcoholics. Clin Exp Immunol 1996;103:304-310. [PubMed: 8565316]

62. Cook RT, Zhu X, Coleman RA, et al. T-cell activation after chronic ethanol ingestion in mice. Alcohol 2004;33:175-181. [PubMed: 15596085] 
63. Frank J, Witte K, Schrodl W, Schutt C. Chronic alcoholism causes deleterious conditioning of innate immunity. Alcohol Alcohol 2004;39:386-392. [PubMed: 15289211]

64. McClain C, Hill D, Schmidt J, Diehl AM. Cytokines and alcoholic liver disease. Semin Liver Dis 1993;13:170-182. [PubMed: 8337603]

65. Sheron N. Alcoholic liver damage - toxicity, autoimmunity and allergy. Clin Exp Allergy 1994;24:503-507. [PubMed: 7922769]

66. Silvain C, Patry C, Launay P, Lehuen A, Monteiro RC. Altered expression of monocyte IgA Fc receptors is associated with defective endocytosis in patients with alcoholic cirrhosis. Potential role for IFN-gamma. J Immunol 1995;155:1606-1618. [PubMed: 7636220]

67. Spies CD, von Dossow V, Eggers V, et al. Altered cell-mediated immunity and increased postoperative infection rate in long-term alcoholic patients. Anesthesiology 2004;100:1088-1100. [PubMed: 15114205]

68. Szabo G. Consequences of alcohol consumption on host defence. Alcohol Alcohol 1999;34:830-841. [PubMed: 10659718]

69. Jayasinghe R, Gianutsos G, Hubbard AK. Ethanol induced suppression of cell-mediated immunity in the mouse. Alcohol Clin Exp Res 1992;16:331-335. [PubMed: 1590554]

70. Nelson S, Kolls J. Alcohol, host defense and society. Nat Rev Immunol 2002;2:205-209. [PubMed: 11913071]

71. Waltenbaugh C, Peterson JD. Ethanol impairs the induction of delayed hypersensitivity in C57BL/6 mice. Alcohol 1997;14:149-153. [PubMed: 9085715]

72. Corrao G, Arico S. Independent and combined action of hepatitis $\mathrm{C}$ virus infection and alcohol consumption on the risk of symptomatic liver cirrhosis. Hepatology 1998;27:911-919.

73. Lau AH, Abe M, Thomson AW. Ethanol affects the generation, cosignaling molecule expression, and function of plasmacytoid and myeloid dendritic cell subsets in vitro and in vivo. J Leukoc Biol 2006;79:941-953. [PubMed: 16478920]

74. Mandrekar P, Catalano D, Dolganiuc A, Kodys K, Szabo G. Inhibition of myeloid dendritic cell accessory cell function and induction of T cell anergy by alcohol correlates with decreased IL-12 production. J lmmunol 2004;173:3398-3407.

75. Szabo G, Dolganiuc A, Mandrekar P, White B. Inhibition of antigen presenting cell functions by alcohol: implications for hepatitis C virus infection. Alcohol 2004;33:211-249.

76. Banchereau J, Steinman RM. Dendritic cells and the control of immunity. Nature 1998;392:245-252. [PubMed: 9521319]

77. Reis E, Souza C. Dendritic cells in a mature age. Nat Rev Immunol 2006;6:476-483. [PubMed: 16691244]

78. Caux C, Massacrier C, Vanbervliet B, et al. Activation of human dendritic cells through CD40 crosslinking. J Exp Med 1994;180:1263-1272. [PubMed: 7523569]

79. Banchereau J, Palucka AK. Dendritic cells as therapeutic vaccines against cancer. Nat Rev Immunol 2005;5:296-306. [PubMed: 15803149]

80. Banchereau J, Palucka AK, Dhodapkar M, et al. Immune and clinical responses in patients with metastatic melanoma to CD34(+) progenitor-derived dendritic cell vaccine. Cancer Res 2001;61:6451-6458. [PubMed: 11522640]

81. Cerundolo V, Hermans IF, Salio M. Dendritic cells: a journey from laboratory to clinic. Nat Immunol 2004;5:7-10. [PubMed: 14699398]

82. Encke J, Findeklee J, Geib J, Pfaff E, Stremmel W. Prophylactic and therapeutic vaccination with dendritic cells against hepatitis C virus infection. Clin Exp Immunol 2005;142:362-369. [PubMed: 16232225]

83. Kuzushita N, Gregory SH, Monti NA, Carlson R, Gehring S, Wands JR. Vaccination with proteintransduced dendritic cells elicits a sustained response to hepatitis $\mathrm{C}$ viral antigens. Gastroenterology 2006;130:453-464. [PubMed: 16472599]

84. Figdor CG, van Kooyk Y, Adema GJ. C-type lectin receptors on dendritic cells and Langerhans cells. Nat Rev Immunol 2002;2:77-84. [PubMed: 11910898]

85. Carlos TM, Harlan JM. Leukocyte endothelial adhesion molecules. Blood 1994;84:2068-2101. [PubMed: 7522621] 
86. Leenen PJ, Radosevic K, Voerman JS, et al. Heterogeneity of mouse spleen dendritic cells: in vivo phagocytic activity, expression of macrophage markers, and subpopulation turnover. J Immunol 1998;160:2166-2173. [PubMed: 9498754]

87. Hochrein H, Shortman K, Vremec D, Scott B, Hertzog P, O'Keefe M. Differential production of IL-12, IFN-alpha, and IFN-gamma by mouse dendritic cell subsets. J Immunol 2001;166:5448-5455. [PubMed: 11313382]

88. Edsen-Moore MR, Fan J, Ness KJ, Marietta JR, Cook RT, Schlucter AJ. Effects of chronic ethanol feeding on murine dendritic cell numbers, turnover rate, and dendropoiesis. Alcohol Clin Exp Res 2008;32:1309-1320. [PubMed: 18540909]

89. Heinz R, Waltenbaugh C. Ethanol consumption modifies dendritic cell antigen presentation in mice. Alcohol Clin Exp Res 2007;31:1759-1771. [PubMed: 17850646]

90. Laso FJ, Vaquero JM, Almeida J, Marcos M, Orfao A. Chronic alcohol consumption is associated with changes in the distribution, immunophenotype, and the inflammatory cytokine secretion profile of circulating dendritic cells. Alcohol Clin Exp Res 2007;31:846-854. [PubMed: 17386065]

91. Waldschmidt TJ, Cook RT, Kovacs EJ. Alcohol and inflammation and immune responses: summary of the 2006 Alcohol and Immunology Research Interest Group (AIRIG) meeting. Alcohol 2008;42:137-142. [PubMed: 18358993]

92. Diepolder HM, Zachoval R, Hoffmann RM, et al. Possible mechanism involving T-lymphocyte response to nonstructural protein 3 in viral clearance in acute hepatitis $\mathrm{C}$ virus infection. Lancet 1995;346:1006-1007. [PubMed: 7475549]

93. Gerlach JT, Diepolder HM, Jung MC, et al. Recurrence of hepatitis C virus after loss of virus-specific CD4(+) T-cell response in acute hepatitis C. Gastroenterology 1999;117:933-941. [PubMed: 10500077]

94. Thimme R, Oldach D, Chang KM, Steiger C, Ray SC, Chisari FV. Determinants of viral clearance and persistence during acute hepatitis C virus infection. J Exp Med 2001;194:1395-1406. [PubMed: 11714747]

95. Frese M, Schwarzle V, Barth K, et al. Interferon-gamma inhibits replication of subgenomic and genomic hepatitis C virus RNAs. Hepatology 2002;35:694-703. [PubMed: 11870386]

96. Thimme R, Bukh J, Spangenberg HC, et al. Viral and immunological determinants of hepatitis C virus clearance, persistence, and disease. Proc Natl Acad Sci U S A 2002;99:15661-15668. [PubMed: 12441397]

97. Takaki A, Wiese M, Maertens G, et al. Cellular immune responses persist and humoral responses decrease two decades after recovery from a single-source outbreak of hepatitis C. Nat Med 2000;6:578-582. [PubMed: 10802716]

98. Mehta SH, Cox A, Hoover DR, et al. Protection against persistence of hepatitis C. Lancet 2002;359:1478-1483. [PubMed: 11988247]

99. Bassett SE, Guerra B, Brasky K, et al. Protective immune response to hepatitis C virus in chimpanzees rechallenged following clearance of primary infection. Hepatology 2001;33:1479-1487. [PubMed: 11391537]

100. Grakoui A, Shoukry NH, Woollard DJ, et al. HCV persistence and immune evasion in the absence of memory T cell help. Science 2003;302:659-662. [PubMed: 14576438]

101. Pham TN, MacParland SA, Mulrooney PM, Cooksley H, Naoumov NV, Michalak TI. Hepatitis C virus persistence after spontaneous or treatment-induced resolution of hepatitis C. J Virol 2004;78:5867-5874. [PubMed: 15140984]

102. Donato F, Tagger A, Gelatti U, et al. Alcohol and hepatocellular carcinoma: the effect of lifetime intake and hepatitis virus infections in men and women. Am J Epidemiol 2002;155:323-331. [PubMed: 11836196]

103. Chisari FV. Unscrambling hepatitis C virus-host interactions. Nature 2005;436:930-932. [PubMed: 16107831]

104. Shoukry NH, Cawthon AG, Walker CM. Cell-mediated immunity and the outcome of hepatitis C virus infection. Annu Rev Microbiol 2004;58:391-424. [PubMed: 15487943]

105. Gehring S, Gregory SH, Wintermeyer P, San Martin M, Aloman C, Wands JR. Generation and charecterization of an immunogenic dendritic cell population. J lmmunol Methods 2008;332:1830 . 
106. Dolganiuc A, Kodys K, Kopasz A, Marshall C, Mandrekar P, Szabo G. Additive inhibition of dendritic cell allostimulatory capacity by alcohol and hepatitis $\mathrm{C}$ is not restored by DC maturation and involves abnormal IL-10 and IL-2 induction. Alcohol Clin Exp Res 2003;27:1023-1031. [PubMed: 12824825]

107. Plumlee CR, Lazaro CA, Fausto N, Polyak SJ. Effect of ethanol on innate antiviral pathways and HCV replication in human liver cells. Virol J 2005;2:89. [PubMed: 16324217]

108. Anand BS, Thornby J. Alcohol has no effect on hepatitis C virus replication: a meta-analysis. Gut 2005;54:1468-1472. [PubMed: 16162952]

109. Pearlman BL, Ehleben C, Saifee S. Treatment extension to 72 weeks of peginterferon and ribavirin in hepatitis c genotype 1-infected slow responders. Hepatology 2007;46:1688-1694. [PubMed: 18046717]

110. Poordad F, Reddy KR, Martin P. Rapid virologic response: a new milestone in the management of chronic hepatitis C. Clin Infect Dis 2008;46:78-84. [PubMed: 18171217]

111. Campbell JV, Hagan II, Latka MH, et al. High prevalence of alcohol use among hepatitis C virus antibody positive injection drug users in three US cities. Drug Alcohol Depend 2006;81:259-265. [PubMed: 16129567]

112. Okazaki T, Yoshihara H, Suzuki K, et al. Efficacy of interferon therapy in patients with chronic hepatitis C. Comparison between non-drinkers and drinkers. Scand J Gastroenterol 1994;29:1039_ 1043. [PubMed: 7871371]

113. Bizollon T, Ahmed SN, Radenne S, et al. Long term histological improvement and clearance of intrahepatic hepatitis $C$ virus RNA following sustained response to interferon-ribavirin combination therapy in liver transplanted patients with hepatitis C virus recurrence. Gut 2003;52:283-287. [PubMed: 12524414]

114. Davis GL, Lau JY. Factors predictive of a beneficial response to therapy of hepatitis C. Hepatology 1997;26:122S-127S. [PubMed: 9305676]

115. Loguercio C, Di Pierro M, Di Marino MP, et al. Drinking habits of subjects with hepatitis C virusrelated chronic liver disease: prevalence and effect on clinical, virological and pathological aspects. Alcohol Alcohol 2000;35:296-301. [PubMed: 10869251]

116. Ohnishi K, Matsuo S, Matsutani K, et al. Interferon therapy for chronic hepatitis $\mathrm{C}$ in habitual drinkers: comparison with chronic hepatitis $\mathrm{C}$ in infrequent drinkers. Am J Gastroenterol 1996;91:1374-1379. [PubMed: 8677998]

117. Tabone M, Sidoli L, Laudi C, et al. Alcohol abstinence does not offset the strong negative effect of lifetime alcohol consumption on the outcome of interferon therapy. J Viral Hepat 2002;9:288-294. [PubMed: 12081606]

118. Kanazawa Y, Hayashi N, Mita E, et al. Influence of viral quasispecies on effectiveness of interferon therapy in chronic hepatitis C patients. Hepatology 1994;20:1121-1130. [PubMed: 7523271] 


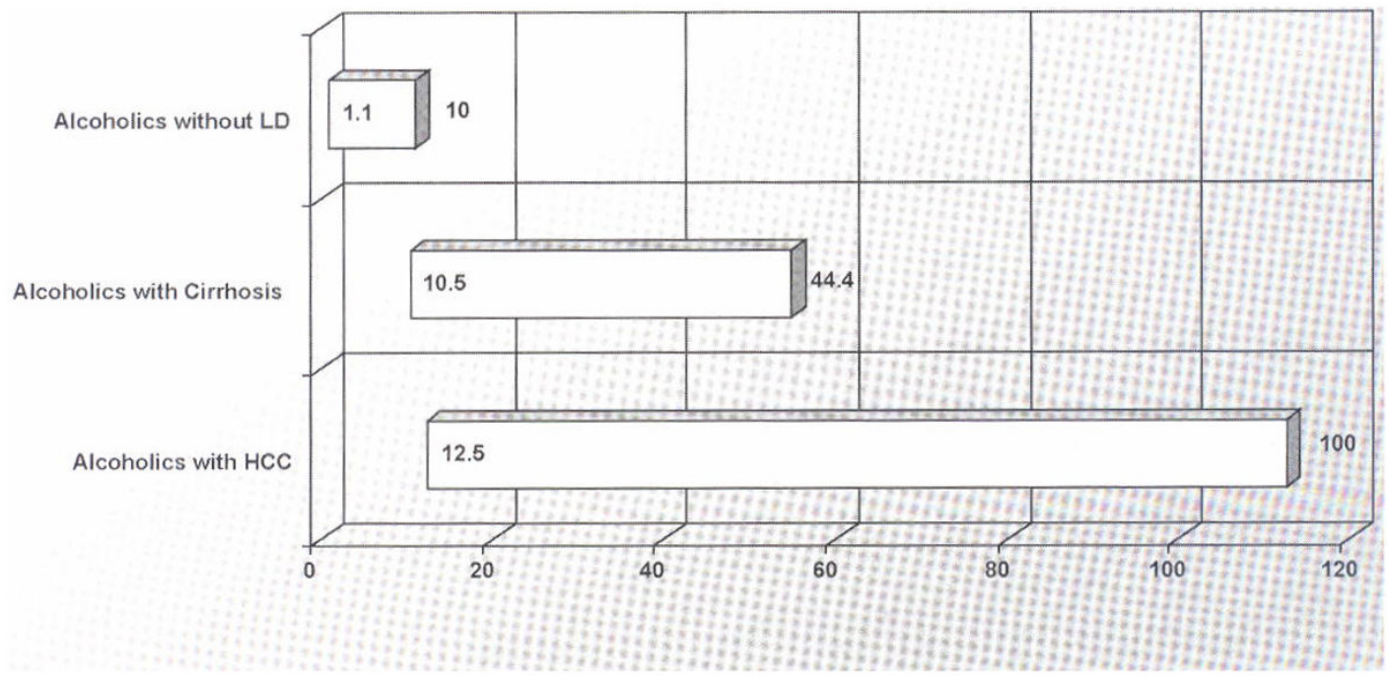

Figure 1.

Prevalence of hepatitis $\mathrm{C}$ virus infection in alcoholics with liver disease (LD). The bar graph represents the range of values found in each category based on studies cited in the text. HCC, hepatocellular carcinoma. 


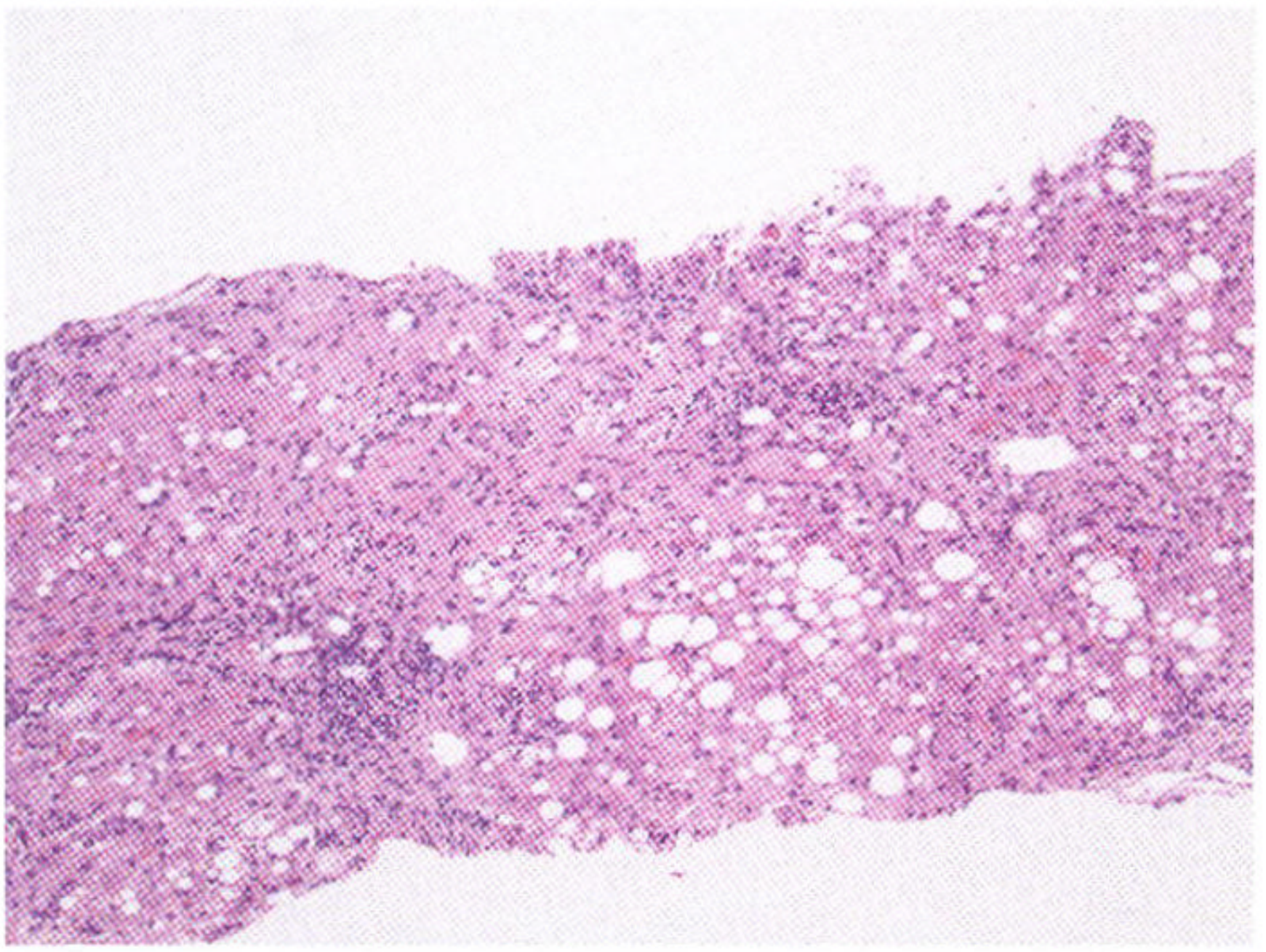

Figure 2.

Histologic appearance of alcohol-induced liver disease and hepatitis $\mathrm{C}$ virus infection. Note the severe lobular disarray, cell dropout, steatosis, fibrosis, and lymphocytic infiltration of the portal areas. 


\section{ETHANOL}

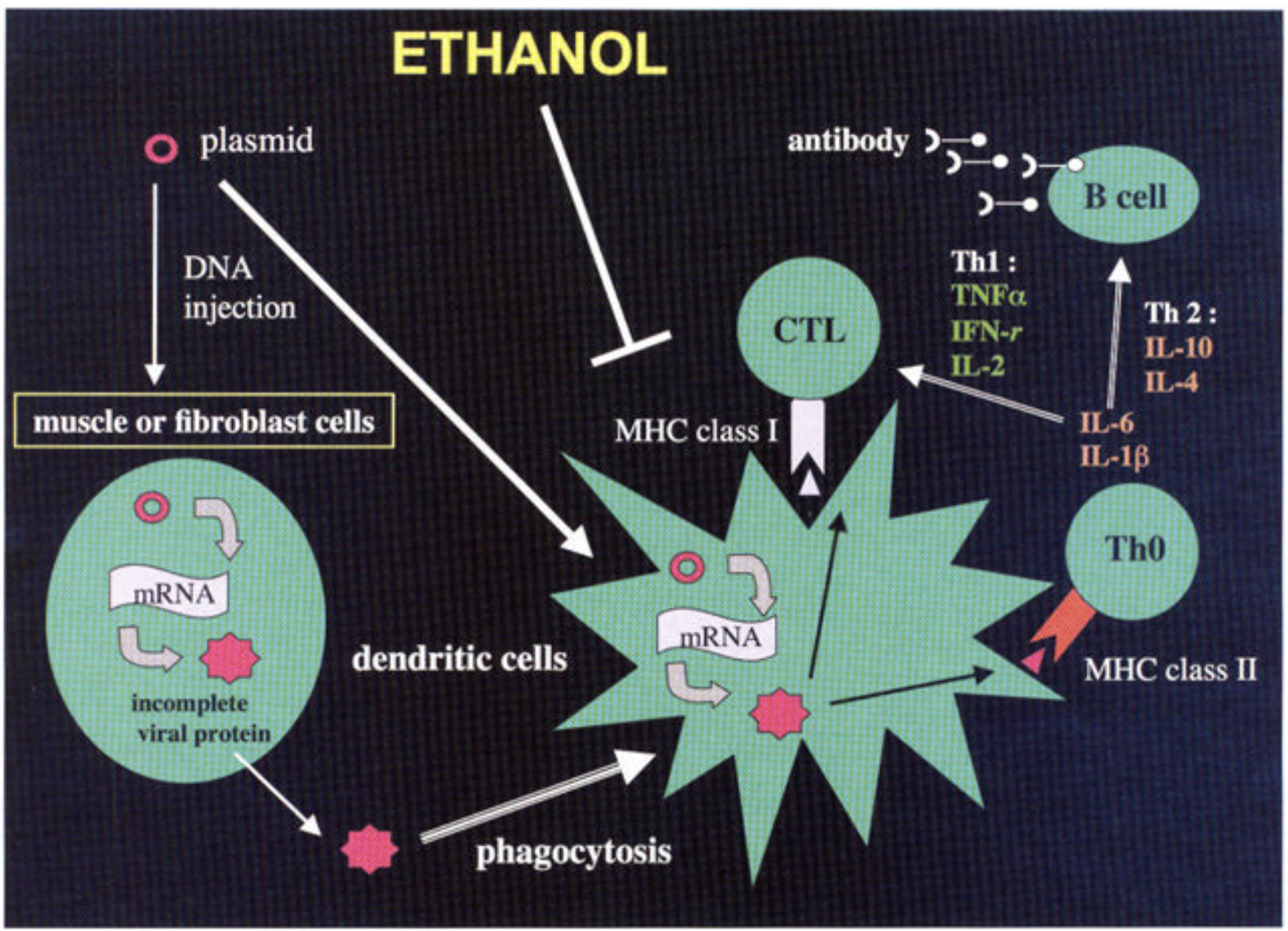

Figure 3.

Diagram illustrating the effect of alcohol on generation of anti hepatitis $\mathrm{C}$ virus (HCV) immune responses following genetic immunization and the central role of dendritic cells (DCs) in this process Genetic immunization is a technique that generates strong cellular immune responses to viral peptides The gene of interest is cloned into a plasmid followed by direct injection into muscle or fibroblastic cells The gene is transcribed and translated, and the protein processed where it may then be picked-up by adjacent DCs by phagocytosis. The viral protein is further processed and expressed on the cell surface with costimulatory proteins in the context of major histocompatibility complex (MHC) class I and class II molecules to activate CD8+ cytotoxic T lymphocyte (CTL) responses as well as CD4+ proliferative activity. The helper T cell (Th0) lymphocytes can mature via Th1 cytokine exposure promoting cellular immune responses or by Th2 cytokines generating B-cell antibody responses. Alcohol has its principal effect on blocking DC activity by poorly understood mechanisms and, therefore, affects both arms of the immune system in response to HCV immunization. DNA, deoxyribonucleic acid, TNF, tumor necrosis factor; IL, interleukin; IFN, interferon; mRNA, messenger ribonucleic acid. 